\title{
Oxygen Profiles in, and in the Agar Beneath, Colonies of Bacillus cereus, Staphylococcus albus and Escherichia coli
}

\author{
By A. C. PETERS, ${ }^{*}$ J. W. T. WIMPENNY AND J. P. COOMBS $\dagger$ \\ Department of Microbiology, University College Cardiff, Newport Road, Cardiff CF2 ITA, UK
}

(Received 3 September 1986; revised 12 December 1986)

This paper reports the use of microelectrodes to measure $\mathrm{O}_{2}$ penetration in different aged colonies of Bacillus cereus, Escherichia coli and Staphylococcus albus. In young (18 h) colonies of $B$. cereus and E. coli $\mathrm{O}_{2}$ disappeared at depths of $25-30 \mu \mathrm{m}$ and $35-40 \mu \mathrm{m}$ respectively. In young $S$. albus colonies, $\mathrm{O}_{2}$ reached a minimum but was never completely absent. As colonies aged (24$168 \mathrm{~h}$ ) the depth to which $\mathrm{O}_{2}$ penetrated increased.

\section{INTRODUCTION}

A bacterial colony obtains nutrients from the solid agar surface on which it develops. Rapid growth leads to steep solute gradients as substrates diffuse upwards into the colony whilst, under aerobic conditions, $\mathrm{O}_{2}$ diffuses downwards. The depth to which $\mathrm{O}_{2}$ penetrates has been estimated previously. Pirt (1967) concluded that in colonies of Escherichia coli, growing at their maximum specific growth rate on a glucose/salts medium, $\mathrm{O}_{2}$ would penetrate to $40 \mu \mathrm{m}$. Wimpenny \& Lewis (1977) investigated the respiration of intact bacterial colonies growing on tryptone-soya agar in respirometer flasks. They calculated that $\mathrm{O}_{2}$ would penetrate to a mean depth of $31 \mu \mathrm{m}, 37 \mu \mathrm{m}$ and $9 \mu \mathrm{m}$ for E. coli, Bacillus cereus and Staphylococcus albus respectively.

A preliminary study by Wimpenny \& Coombs (1983) used commercial $\mathrm{O}_{2}$ microelectrodes to measure the partial pressure of $\mathrm{O}_{2}$ in and around an $18 \mathrm{~h}$ colony of $B$. cereus directly. They found steep $\mathrm{O}_{2}$ gradients at the colony surface with $\mathrm{O}_{2}$ penetrating to a depth of $25-30 \mu \mathrm{m}$. Bungay et al. (1983) have also used $\mathrm{O}_{2}$ microelectrodes to measure gradients in Pseudomonas ovalis colonies. They also demonstrated steep gradients and found that the extent of $\mathrm{O}_{2}$ penetration varied with substrate concentration. Coombs \& Peters (1985) developed a method for producing simple, inexpensive and reliable $\mathrm{O}_{2}$ microelectrodes with a typical tip diameter of $5 \mu \mathrm{m}$. These have allowed further investigations and in this paper we report on the penetration of $\mathrm{O}_{2}$ in and around colonies of $E$. coli, B. cereus and $S$. albus at different times after inoculation.

\section{METHODS}

Organisms and culture conditions. Cultures of Bacillus cereus C11, Escherichia coli $\mathrm{K} 12$ and Staphylococcus albus NCIB 8558 were obtained from the departmental culture collection. The organisms were maintained and grown on TSBA medium containing ( $\mathrm{g} \mathrm{l}^{-1}$ ): tryptic soy broth (Difco), 30; agar (Difco), 15. Plates were poured on a level surface and dried for $1-1.5 \mathrm{~h}$ at $37^{\circ} \mathrm{C}$. The plates were inoculated from a confluent lawn plate using a glass needle freshly drawn from a Pasteur pipette. Care was taken to avoid breaking the agar surface. Up to three colonies were inoculated on each plate and the latter were incubated in a water saturated environment at $30^{\circ} \mathrm{C}$. For experiments with $E$. coli and $S$. albus a single $B$. cereus colony was inoculated $24 \mathrm{~h}$ before measurements were due to be made. This colony was used to calibrate the electrode zero before it was deployed in a colony in which the characteristic penetration of $\mathrm{O}_{2}$ was not known. Wimpenny \& Coombs (1983) demonstrated that a zone which extended from $25 \mu \mathrm{m}$ to $100 \mu \mathrm{m}$ below the surface of an $18 \mathrm{~h} \mathrm{~B}$. cereus colony was anoxic, using electrodes calibrated in a ferrous sulphide slurry. In the investigations described here it was assumed that a $0 \%$ partial pressure of $\mathrm{O}_{2}\left(\mathrm{pO}_{2}\right)$ was obtained between 40 and $50 \mu \mathrm{m}$ below the surface of a $24 \mathrm{~h} \mathrm{~B}$. cereus colony. The $100 \% \mathrm{pO}_{2}$ was assumed to be that partial pressure found on the surface of an air saturated agar plate.

$\dagger$ Present address: Ministry of Agriculture Fisheries and Food, Slough Laboratory, London Road, Slough SL3 7HJ, UK. 
$\mathrm{O}_{2}$ measurements. Two different types of electrode were used to collect the data. Work with $B$. cereus was done using a commercially a vailable $\mathrm{O}_{2}$ sensitive microelectrode (model 723, Transidyne, Ann Arbor, Michigan, USA). All other work was done using electrodes made by the method described by Coombs \& Peters (1985). The electrodes were mounted on a micromanipulator (Prior) which allowed vertical movement accurate to $5 \mu \mathrm{m}$ and horizontal movement in two planes to an accuracy of $100 \mu \mathrm{m}$. The microelectrode and a silver/silver chloride reference electrode were connected to a Transidyne chemical microsensor (model 1201) which was used to measure the $\mathrm{pO}_{2}$. During measurements the reference electrode was inserted in the agar at the edge of the plate. All the apparatus was mounted inside an earthed Faraday cage which reduced unwanted electrical noise. Using the micromanipulator it was possible to position the electrode above the colony and probe the colony and agar below it to a depth of $800 \mu \mathrm{m}$. The profile of the colony was also measured by noting the distance between the surface of the colony and a fixed position above it.

\section{RESULTS AND DISCUSSION}

Figs 1-3 show the distribution of $\mathrm{O}_{2}$ in and around different aged colonies of B. cereus, E. coli and $S$. albus.

In an $18 \mathrm{~h} \mathrm{~B}$. cereus colony (Fig. 1 a) $\mathrm{O}_{2}$ penetrated to a depth of $25-30 \mu \mathrm{m}$. The anoxic zone extended from $25 \mu \mathrm{m}$ below the surface to roughly the base of the colony. $\mathrm{O}_{2}$ was depleted from the underlying agar with a $\mathrm{pO}_{2} 50 \%$ of the air saturated value $700-800 \mu \mathrm{m}$ below the colony base. As the colonies aged (Fig. $1 b, c, d$ ) the anoxic zone extended into the agar below the colony. The depth to which $\mathrm{O}_{2}$ penetrated the colony surface increased slightly but never to more than $50 \mu \mathrm{m}$. In the $68 \mathrm{~h}$ colony (Fig. $1 d$ ) the anoxic zone extended $250 \mu \mathrm{m}$ below the colony base. In colonies older than about $120 \mathrm{~h}$ (not shown) the anoxic zone disappeared as $\mathrm{O}_{2}$ diffused back into the colony which by then was probably nutrient limited. In a $168 \mathrm{~h}$ colony (Fig. $1 e$ ) the lowest $\mathrm{pO}_{2}$ found was $5 \%$. The $\mathrm{O}_{2}$ gradient from the surface into the colony was much shallower than that found in young colonies.

In an $18 \mathrm{~h}$ colony of $E$. coli (Fig. $2 a$ ) $\mathrm{O}_{2}$ penetrated to a depth of $35-40 \mu \mathrm{m}$ below the surface. The anoxic zone extended some $200 \mu \mathrm{m}$, up to $50 \mu \mathrm{m}$ below the base of the colony. The partial pressure of $\mathrm{O}_{2}$ in the agar was depleted, the $50-70 \%$ air saturation isopleth occurring at a depth of $800 \mu \mathrm{m}$. In the $24 \mathrm{~h}$ colony the position of the anoxic zone had not changed much but the $\mathrm{pO}_{2}$ had dropped to $40 \%$ at $800 \mu \mathrm{m}$ below the colony base (Fig. $2 b$ ). As the colonies aged (Fig. $2 c, d$ ) $\mathrm{O}_{2}$ penetration increased to $70 \mu \mathrm{m}$ and $\mathrm{O}_{2}$ saturation in the agar fell to around $10 \%$ at $800 \mu \mathrm{m}$ in a $68 \mathrm{~h}$ colony. In a $168 \mathrm{~h}$ colony $\mathrm{O}_{2}$ penetrated $200 \mu \mathrm{m}$ at the centre of the colony and the anoxic zone extended below the $800 \mu \mathrm{m}$ limit of measurement (Fig. $2 e$ ). $\mathrm{O}_{2}$ gradients were steeper at the edges of the colony probably because cells in this region were still respiring actively and had not become substrate limited.

In an $18 \mathrm{~h} \mathrm{~S}$. albus colony $\mathrm{O}_{2}$ penetrated throughout the colony, reaching a minimum of $15 \%$ at $50-60 \mu \mathrm{m}$ below the surface (Fig. $3 a$ ). $\mathrm{O}_{2}$ gradients at the periphery of the colony were no steeper than that found at the centre. As the colony aged the minimum $\mathrm{pO}_{2}$ dropped. At $44 \mathrm{~h}$ (Fig. $3 b$ ) a minimum of $5 \%$ was seen $70 \mu \mathrm{m}$ below the surface. In an $80 \mathrm{~h}$ colony (Fig. $3 c$ ) this value had dropped to $4 \%$ and $\mathrm{O}_{2}$ in the agar was further depleted. The penetration of $\mathrm{O}_{2}$ into older colonies was not fully investigated; however, preliminary studies in a $168 \mathrm{~h}$ colony showed that $\mathrm{pO}_{2}$ was at about $90-95 \%$ thoughout the colony and underlying agar. This suggested that respiration rates had fallen to low levels and that $\mathrm{O}_{2}$ had now diffused back into the system.

When apparent plateaus of measurable $\mathrm{O}_{2}$ were found in $S$. albus colonies it was feared that the performance of the electrode was in some way affected and that these plateaus were in fact anoxic zones. When recording the $\mathrm{pO}_{2}$ manually using the chemical microsensor it was only possible to obtain readings to an accuracy of about $1 \%$. Accuracy was improved by logging data from the chemical microsensor on a BBC model B microcomputer. This demonstrated that the limit with $S$. albus represented an $\mathrm{O}_{2}$ minimum rather than a plateau.

Fig. 4 shows profiles of $\mathrm{O}_{2}$ penetration through colonies of $S$. albus and B. cereus. In the two $48 \mathrm{~h} S$. albus colonies a minimum $\mathrm{pO}_{2}$ was clearly reached although the gradient was very shallow, covering a range of only about $1 \%$. The control profile through a $48 \mathrm{~h} \mathrm{~B}$. cereus colony shows that a true zero is obtained with a large plateau observed throughout the anaerobic zone. 


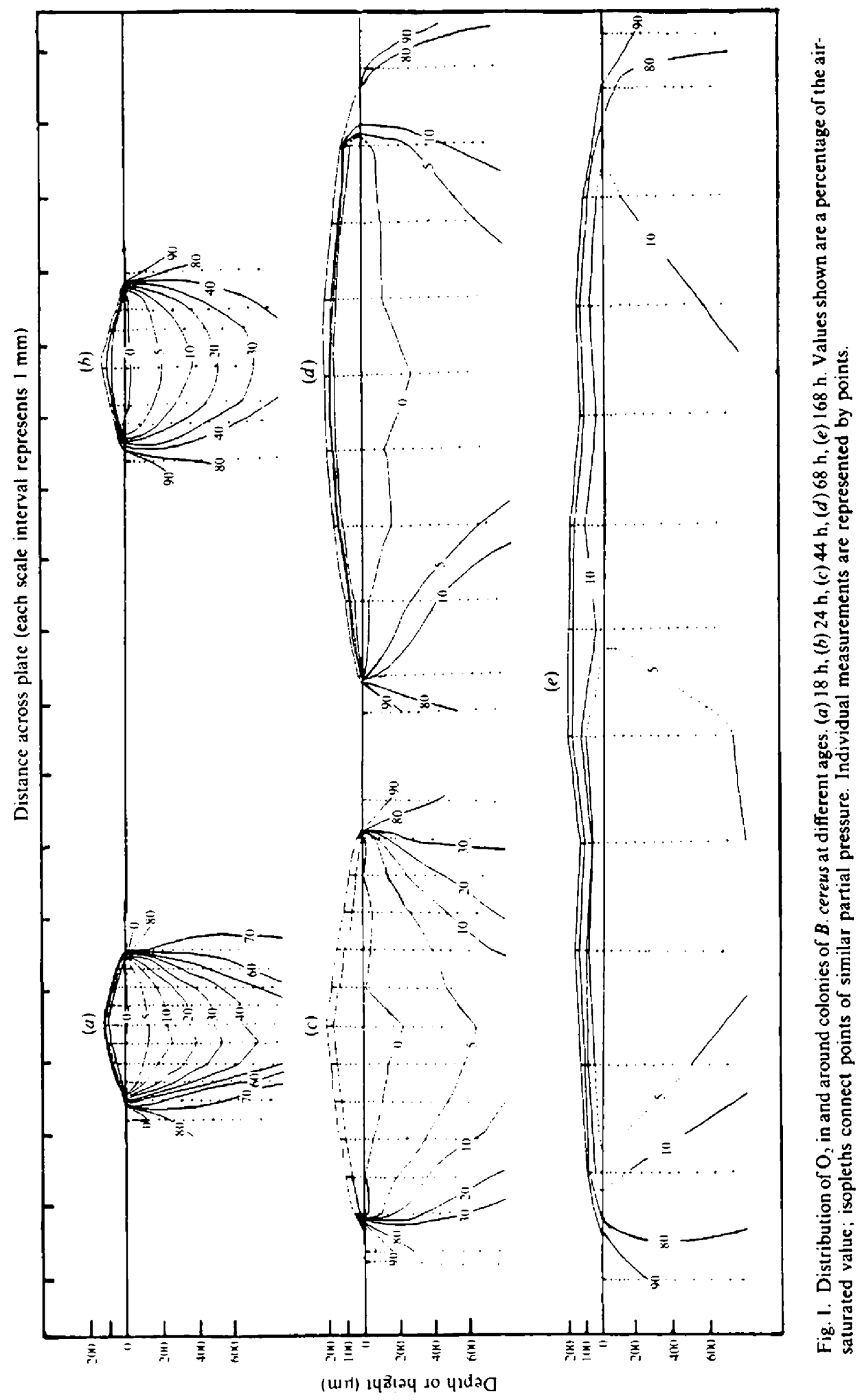




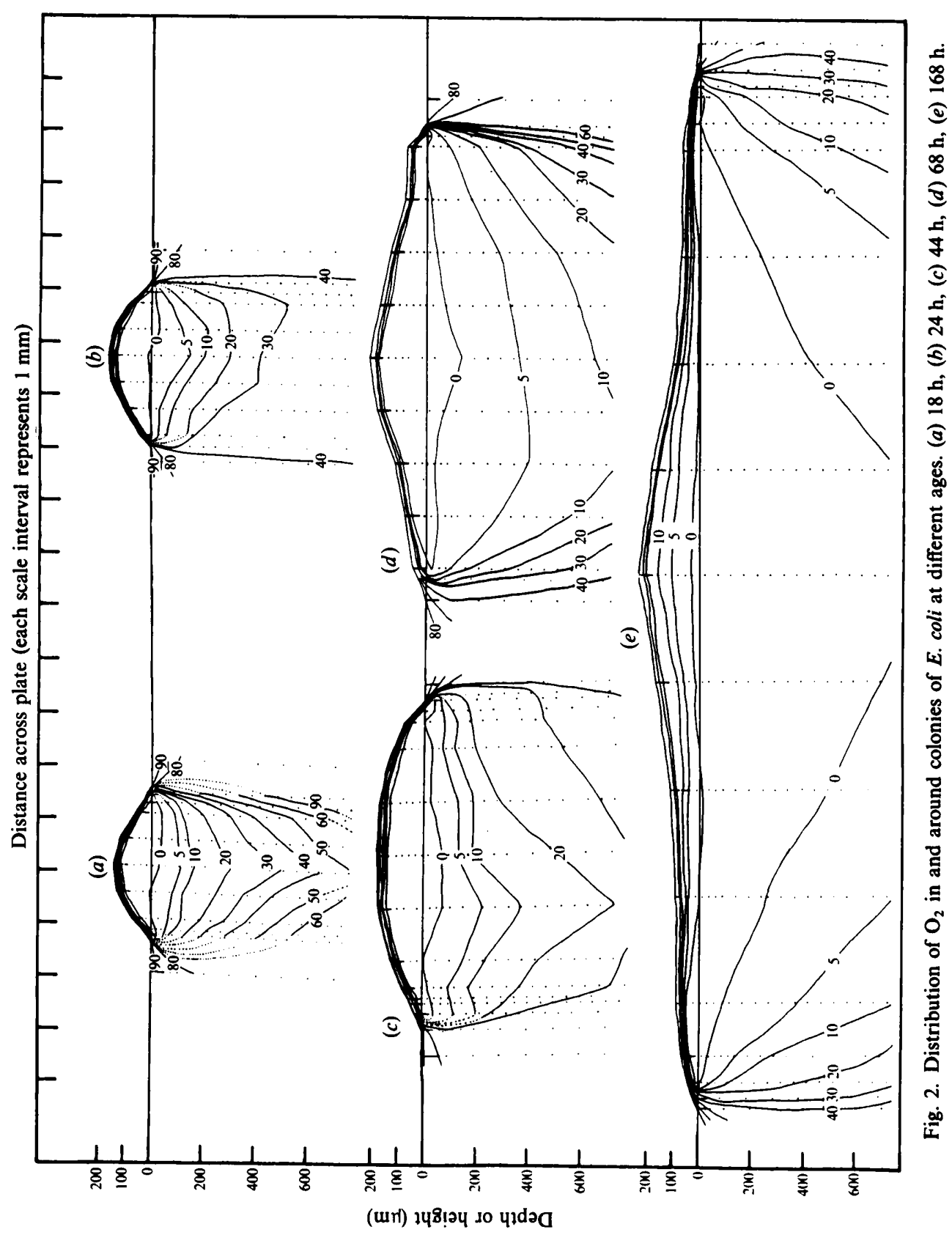


Distance across plate (each scale interval represents $1 \mathrm{~mm}$ )

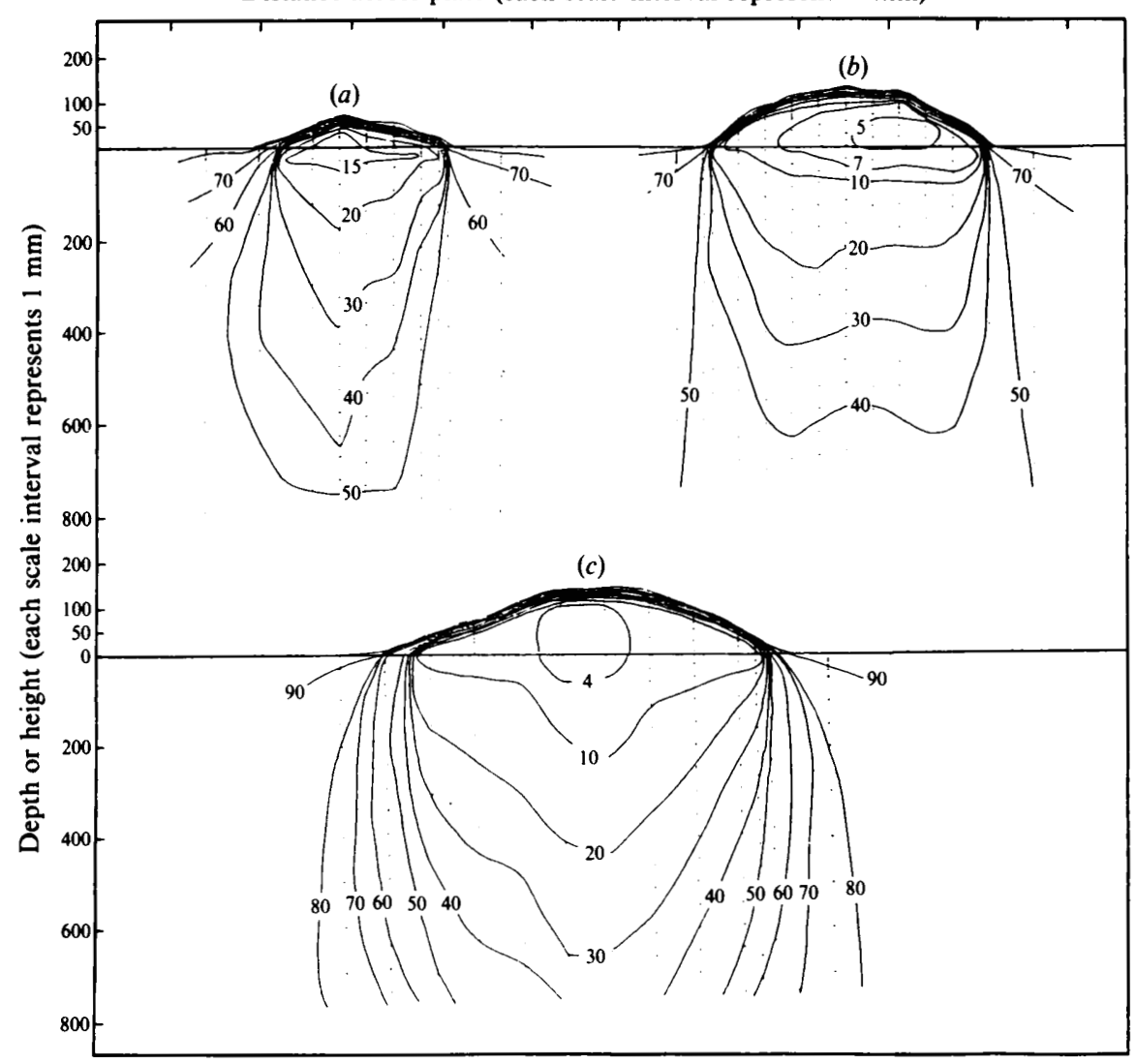

Fig. 3. Distribution of $\mathrm{O}_{2}$ in and around colonies of $S$. albus at different ages. (a) $18 \mathrm{~h},(\mathrm{~b}) 44 \mathrm{~h},(c) 80 \mathrm{~h}$.

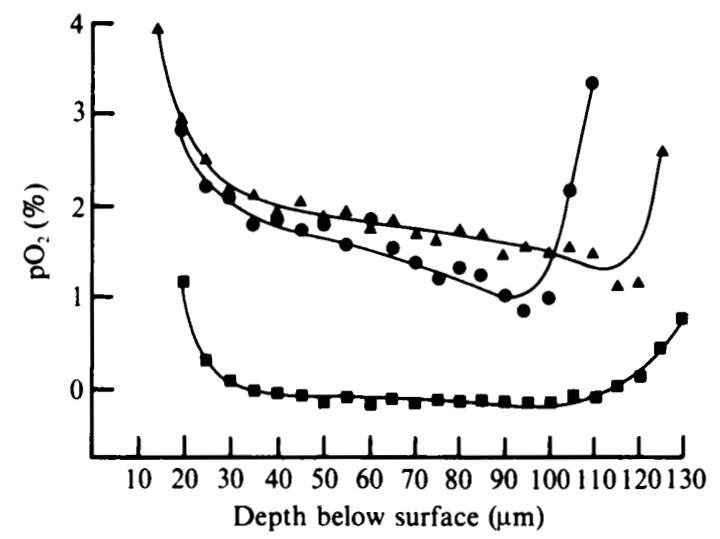

Fig. 4. Profiles through colonies of $48 \mathrm{~h} S$. albus, $(\boldsymbol{A}, O)$ and $B$. cereus $(\square) . \mathrm{O}_{2}$ concentration is expressed as a $\%$ of the air saturated value.

Preliminary work by Wimpenny \& Coombs (1983) showed the value of using polarographic oxygen microelectrodes for the direct measurement of $\mathrm{O}_{2}$ in a bacterial colony. The development of inexpensive, reliable microelectrodes has allowed further investigations to be made.

Values for the penetration of $\mathrm{O}_{2}$ in all three types of colony can be compared with those 
Table 1. Respiration rates determined from $\mathrm{O}_{2}$ penetration data at different points across colonies of $B$. cereus and E. coli

\begin{tabular}{|c|c|c|c|c|c|c|}
\hline \multirow[b]{2}{*}{$\begin{array}{l}\text { Colony } \\
\text { age } \\
\text { (h) }\end{array}$} & \multicolumn{3}{|c|}{ B. cereus ${ }^{*}$} & \multicolumn{3}{|c|}{ E. coli ${ }^{*}$} \\
\hline & $\begin{array}{l}\text { Edge of } \\
\text { colony }\end{array}$ & $\begin{array}{l}\text { Midpoint } \\
\text { between } \\
\text { edge and } \\
\text { centre }\end{array}$ & $\begin{array}{l}\text { Centre } \\
\text { of } \\
\text { colony }\end{array}$ & $\begin{array}{l}\text { Edge of } \\
\text { colony }\end{array}$ & $\begin{array}{l}\text { Midpoint } \\
\text { between } \\
\text { edge and } \\
\text { centre }\end{array}$ & $\begin{array}{l}\text { Centre } \\
\text { of } \\
\text { colony }\end{array}$ \\
\hline 18 & 445 & 445 & 309 & 309 & 309 & 227 \\
\hline 24 & 445 & 445 & 309 & 445 & 445 & 227 \\
\hline 48 & 445 & 309 & 227 & 445 & 309 & 174 \\
\hline 60 & 309 & 227 & 137 & 309 & 227 & 174 \\
\hline 168 & - & - & - & 445 & 49 & 6 \\
\hline
\end{tabular}

predicted by Wimpenny \& Lewis (1977). They calculated a penetration of $31 \mu \mathrm{m}, 37 \mu \mathrm{m}$ and $9 \mu \mathrm{m}$ for $E$. coli, B. cereus and $S$. albus respectively. Measured values were $35-40 \mu \mathrm{m}$ and $25-$ $30 \mu \mathrm{m}$ for $E$. coli and $B$. cereus respectively, while $S$. albus never appeared to become totally anoxic. One reason for the difference between calculated and measured penetration may be that mathematical calculations were based on the assumption that the shape of a non-spreading colony can be regarded as a segment of a sphere. Whilst this is a good assumption it is not strictly accurate. Another factor which could affect penetration is the rate of diffusion of $\mathrm{O}_{2}$ into a particular colony. This will almost certainly vary depending on the nature of any extracellular polymers produced by the organisms and on the way the individual cells pack in the colony. The results obtained with $S$. albus are unexpected; they suggest either that cellular respiration rates are fundamentally very slow or, perhaps more likely, that the $K_{\mathrm{m}}$ for cytochrome oxidase enzymes is very high in this organism. Such predictions need to be confirmed.

The time course of $\mathrm{O}_{2}$ profile changes indicated steep $\mathrm{O}_{2}$ gradients in the early phases. This was almost certainly due to rapid growth on a plentiful supply of nutrients. As the colonies aged, $\mathrm{O}_{2}$ moved deeper into the structure, suggesting that cells became more and more nutrient limited. In the oldest colonies of $B$. cereus $\mathrm{O}_{2}$ was never exhausted, confirming that reductant rather than oxidant now limited growth rate throughout the colony.

The spatial heterogeneity of growing colonies should be emphasized. It is predicted (Pirt, 1967; Wimpenny, 1979) that exponential growth only occurs at the growing colony margin. Here substrates are in excess and oxygen requirements are at their maximum leading to the observed steep $\mathrm{O}_{2}$ gradients. Pirt (1967) stated that the depth to which a nutrient penetrates a metabolizing tissue is limited by

$$
h g=\sqrt{\frac{2 D s_{0}}{q}}
$$

where $h g(\mathrm{~cm})$ is the depth of penetration, $D\left(\mathrm{~cm}^{2} \mathrm{~s}^{-1}\right)$ is the diffusion coefficient for the nutrient, $s_{0}\left(\mathrm{~g} \mathrm{~cm}^{-3}\right)$ is the concentration of nutrient at the surface and $q$ [g nutrient consumed $\left(\mathrm{cm}^{3} \text { of tissue }\right)^{-1} \mathrm{~s}^{-1}$ ] is the metabolic quotient. By assuming values for $D$ and $s_{0}$ for $\mathrm{O}_{2}$ and having measured the penetration of $\mathrm{O}_{2}$ it is possible to calculate $q$ at different positions in the colony. These values of $q$ may be converted to $Q_{\mathrm{O}_{2}}\left[\mathrm{ml} \mathrm{O}_{2}\left(\mathrm{~g}\right.\right.$ organism dry wt) ${ }^{-1} \mathrm{~h}^{-1}$ ] measurements by assuming a cell concentration [g organism dry wt $\left(\mathrm{cm}^{3} \text { colony }\right)^{-1}$ ]. Table 1 shows $Q_{\mathrm{O}_{2}}$ calculations for $B$. cereus and $E$. coli assuming $D=1.9 \times 10^{-5} \mathrm{~cm}^{2} \mathrm{~s}^{-1}$, $s_{0}=8 \times 10^{-6} \mathrm{~g} \mathrm{~cm}^{-3}$ (Pirt, 1967), and that the cell concentration $=0.275 \mathrm{~g}$ organism dry wt $\left(\mathrm{cm}^{3}\right.$

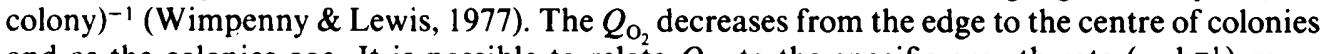
and as the colonies age. It is possible to relate $Q_{\mathrm{O}_{2}}$ to the specific growth rate $\left(\mu, \mathrm{h}^{-1}\right)$ as

$$
\mu=\frac{Q_{\mathrm{O}_{2}} Y_{\mathrm{O}_{2}}}{x}
$$


where $Y_{\mathrm{O}_{2}}$ is the yield coefficient [ $\mathrm{g}$ dry wt tissue $\left(\mathrm{cm}^{3} \text { nutrient }\right)^{-1}$ ] for $\mathrm{O}_{2}$ and $x$ is the cell concentration. However, it proved impossible to calculate $\mu$ as $Y_{\mathrm{O}_{2}}$ had not been measured and probably varies throughout the colony. The change in $Q_{\mathrm{O}_{2}}$ and hence $\mu$ suggest that there is almost certainly a radial substrate gradient from the edge to the colony centre. Spatial heterogeneity implies that the global colony mass increase is only a crude average of a range of values. Indeed Lewis \& Wimpenny (1981) showed that mass increase, though close to exponential in the early stages of growth, gradually dropped to lower values as parts of the colony became increasingly nutrient limited.

Fraleigh \& Bungay (1986) have simulated $\mathrm{O}_{2}$ and substrate gradients as a first step in obtaining a detailed colony growth model. Despite major simplifications in the definition of the colony system the model yielded results which were similar to those from microelectrode studies. It is clear that further detailed investigations of solute gradients within colonies are needed as these together with accurate theoretical models will help to explain colony morphogenesis and differences in morphology from species to species.

Adrian Peters was supported by a Natural Environment Research Council research studentship which we gratefully acknowledge.

\section{REFERENCES}

Bungay, H. R., Pettit, P. M. \& Drislane, A. M. (1983). Dissolved oxygen contours in Pseudomonas ovalis colonies. In American Chemical Society Symposium Series, vol. 207, pp. 395-402. Edited by $\mathrm{H}$. Blanch, E. T. Papoutsakis \& G. Stephanopoulos. Washington, DC: American Chemical Society.

COOMrs, J. P. \& Peters, A. C. (1985). A simple method for making microelectrodes to measure oxygen. Journal of Microbiological Methods 3, 199-204.

Fraleigh, S. P. \& Bungay, H. R. (1986). Modelling of nutrient gradients in a bacterial colony. Journal of General Microbiology 132, 2057-2060.

LeWIS, M. W. A. \& WimpenNy, J. W. T. (1981). The influence of nutrition and temperature on the growth of colonies of Escherichia coli K12. Canadian Journal of Microbiology 27, 679-684.

PIRT, S. J. (1967). A kinetic study of the mode of growth of surface colonies of bacteria and fungi. Journal of General Microbiology 47, 181-197.

WiMPENNY, J. W. T. (1979). The growth and form of bacterial colonies. Journal of General Microbiology $114,483-486$.

Wimpenny, J. W. T. \& Coombs, J. P. (1983). Penetration of oxygen into bacterial colonies. Journal of General Microbiology 129, 1239-1242.

WimpenNY, J. W. T. \& LeWIS, M. W. A. (1977). The growth and respiration of bacterial colonies. Journal of General Microbiology 103, 9-18. 